\title{
An audit of specimens received for superficial fungal studies to the Department of Microbiology, University of Ruhuna
}

\author{
H Thabrew ${ }^{1}$, KGR Nilanthi ${ }^{1}$, A Liyanage ${ }^{2}$, A Gunasekera ${ }^{1}$, NP Weerasinghe ${ }^{1}$, SS Wickramasinghe ${ }^{1}$, \\ S Gunasena $^{1}$, WMDGB Wijayaratne ${ }^{1}$, A De S Nagahawatte ${ }^{1}$
}

\section{Introduction}

Rising numbers of recalcitrant dermatophytoses have been observed in the recent past along with changes in the pattern of the organisms causing dermatophyte infections. The objective was to audit the clinical diagnosis using direct microscopic and/ or mycological culture findings of specimens received from patients clinically suspected with superficial fungal infections.

\section{Methods}

Skin, hair, and nail specimens of patients with suspected superficial fungal infections received at the Department of Microbiology, Faculty of Medicine, University of Ruhuna from $1^{\text {st }}$ January 2018 to $31^{\text {st }}$ December 2019 were audited. Demographic, clinical and direct microscopic and culture results obtained from the records were included in the analysis.

\section{Results}

A total of 651 specimens were included, $60 \%$ of which were from females. The median (Interquartile range) age was 38 years $(24-52)$. Clinical details were documented in $319(49 \%)$ request forms. Significant microscopic and/or culture findings were present in 205 of the 651 specimens (31\%) of which 63\% (130/205) were compatible with documented clinical details while $71 / 205$ were accompanied by request forms with no documented clinical details. Fungal infection of the nails was the commonest documented superficial fungal infection $(182 / 319,57 \%)$ of which $91(50 \%)$ had significant mycological findings. Tinea corporis was the second commonest suspected condition in the study sample $(64 / 319,20 \%)$ with significant microscopic/culture positive findings present in $40(62 \%)$ specimens. Tinea capitis was suspected in 52/319 patients (12\%). However only $4(8 \%)$ specimens had significant positive mycological findings. Significant positive direct microscopic and/ or culture findings were seen with 8 (25\%) of the 32 specimens from patients with suspected tinea pedis and 13 (54\%) of 24 specimens from patients with suspected tinea incognito. Dermatophytes were isolated from 31 specimens while positive direct microscopic findings were seen in 320 specimens.

Table 1: Summary of findings

\begin{tabular}{lccccc}
\hline & \multicolumn{2}{c}{$\begin{array}{c}\text { Clinically } \\
\text { suspected }\end{array}$} & \multicolumn{2}{c}{$\begin{array}{c}\text { Mycologically } \\
\text { proven }\end{array}$} & $\begin{array}{c}\text { Dermatophytes } \\
\text { isolated }\end{array}$ \\
\cline { 2 - 6 } & number & $\%$ & number & $\%$ & Number \\
\hline Total & 319 & 46 & 205 & 31 & 31 \\
Onychomycosis & 182 & 57 & 91 & 50 & 5 \\
Tinea corporis & 64 & 20 & 40 & 62 & 13 \\
Tinea capitis & 52 & 12 & 4 & 8 & 1 \\
Tinea pedis & 32 & 10 & 8 & 25 & 0 \\
Tinea incognito & 24 & 7 & 13 & 54 & 3 \\
Tinea cruris & 5 & 1 & 3 & 60 & 1 \\
\hline
\end{tabular}

\section{Conclusion}

The findings of our audit show that $31 \%$ of the specimens had significant positive results. The compatibility of the clinical suspicions with the microscopic and mycological investigation findings was $63 \%$ in the studied sample. Nail was the commonest specimen received for superficial fungal studies with significant microscopic and culture findings in $50 \%$ of them.

Keywords: Audit, Dermatophytosis, Sri Lanka.

\footnotetext{
${ }^{1}$ Department of Medical Microbiology, Faculty of Medicine, University of Ruhuna, Sri Lanka

${ }^{2}$ Department of Community Medicine, Faculty of Medicine, University of Ruhuna.

Address for correspondence: Dr H Thabrew.+94718411697 Email: harshanipj@gmail.com

(iD https://orcid.org/0000-0002-3049-3585
} 